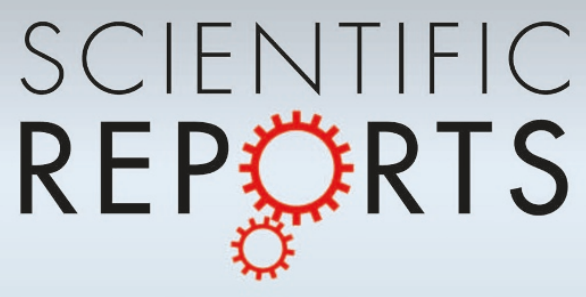

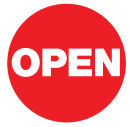

SUBJECT AREAS:

BIOMEDICAL

ENGINEERING

NANOFABRICATION AND NANOPATTERNING

FUEL CELLS

ELECTROCATALYSIS

Received

3 August 2012

Accepted

31 December 2012

Published

6 February 2013

Correspondence and requests for materials should be addressed to

D.E. (de54@cornell.

edu)

\section{High volumetric power density, non-enzymatic, glucose fuel cells}

\author{
Vlad Oncescu \& David Erickson
}

Sibley School of Mechanical and Aerospace Engineering, Cornell University, Ithaca, NY 14853, United States.

The development of new implantable medical devices has been limited in the past by slow advances in lithium battery technology. Non-enzymatic glucose fuel cells are promising replacement candidates for lithium batteries because of good long-term stability and adequate power density. The devices developed to date however use an "oxygen depletion design" whereby the electrodes are stacked on top of each other leading to low volumetric power density and complicated fabrication protocols. Here we have developed a novel single-layer fuel cell with good performance $\left(2 \mu \mathrm{W} \mathrm{cm}{ }^{-2}\right)$ and stability that can be integrated directly as a coating layer on large implantable devices, or stacked to obtain a high volumetric power density (over $16 \mu \mathrm{W} \mathrm{cm} \mathrm{cm}^{-3}$ ). This represents the first demonstration of a low volume non-enzymatic fuel cell stack with high power density, greatly increasing the range of applications for non-enzymatic glucose fuel cells.

$\mathrm{N}$ on-rechargeable lithium batteries have been successfully used in implantable medical devices for over 40 years, however their life cycle is often much shorter than the desired period of implantation for such devices $^{1}$. For example, over $20 \%$ of the 200,000 annual pacemaker implants in the United States are performed in order to replace depleted batteries, whose lifetimes are limited to 5 to 7 years ${ }^{2}$. This results in unnecessary infection risks, inconvenience to patients, and billions of dollars in costs to the health care system. In addition, due to advances in biosensors and low-power electronics, a host of new implantable systems such as pacing devices to prevent congestive heart failure, cochlear implants to treat profound deafness, and deep brain simulators to treat symptoms of Parkinson's disease have been proposed ${ }^{3}$. Because such devices have higher power requirements than pacemakers and have very short lifetimes when powered by current batteries ${ }^{4}$, researchers are developing new implantable power sources that can harvest chemical, thermal and mechanical energy from the human body as an alternative to lithium batteries ${ }^{5,6}$. These include piezoelectric ${ }^{7-9}$ and thermal generators ${ }^{10}$ and bio-fuel cells ${ }^{11-13}$. Glucose fuel cells are particularly interesting because of the abundance of oxygen and glucose in body tissue and the possibility to generate a stable high continuous power output through the coupling of the glucose oxidation and oxygen reduction reactions ${ }^{14}$. In the past few decades most research in the field has been focused on immobilization methods for enzymatic catalysts in an effort to increase the lifetime of glucose fuel cells ${ }^{15}$. Enzymatic catalysts for glucose $/ \mathrm{O}_{2}$ fuel cells have excellent selectivity and can produce power densities of the order of several $\mathrm{mWcm}^{-2}$ however they have very short lifetime, typically less than 30 days, due to the fragile nature of the enzymes and poor immobilization techniques ${ }^{16,17}$. This makes them generally unsuitable for long-term implantable application $s^{18}$ despite having been successfully tested in-vivo ${ }^{19-21}$.

Recently, there has been renewed interest in non-enzymatic fuel cells that use platinum alloys or activated carbon as catalysts ${ }^{14}$. Such fuel cells have shown good time stability and have been successfully tested in-vivo ${ }^{22,23}$. The biggest challenge however remains the poor anode selectivity towards glucose oxidation in the presence of oxygen. Due to the lack of abiotic catalysts to selectively catalyze glucose oxidation, several groups have developed fuel cell designs that reduce the access of oxygen to the anode. An oxygen depletion design that has been commonly used involves placing a porous cathode in front of the anode, such that most of the oxygen gets reduced prior to reaching the anode, allowing glucose oxidation to proceed at low oxygen concentrations. The design first presented by Rao $\mathrm{et} \mathrm{al}^{24}$ in the 1970s made use of hydrogels to separate the porous anode and cathode. Kerzenmacher et al ${ }^{25}$ also used hydrogels as binder for the catalytic materials at the anode and cathode. More recent designs however have avoided the use of hydrogels and instead used porous membranes such as carbon paper or anodized aluminum membranes, as supports for the cathode catalyst. In a previous paper, we demonstrated that such fuel cells can be assembled without a separation membrane in order to improve glucose diffusion to the anode and reduce the thickness of the fuel cell ${ }^{26}$. Although a promising approach, such oxygen depletion designs still require a large volume due to the thickness of each stacked electrode and the inter-electrode space, in addition to complicated fabrication and assembly protocols. The power density for such fuel cells is commonly 
reported in terms of electrode surface area exposed to interstitial fluid instead of volume as is often the case for other power sources. For example, most depletion design fuel cells described in literature have in-vitro power densities ranging from $2 \mu \mathrm{Wcm}^{-2}$ to $4.4 \mu \mathrm{Wcm}^{-2}$, however the assembled devices require volumes of over $2 \mathrm{~cm}^{3}$ because of the need to hold the stacked electrodes together ${ }^{27}$. This results in volumetric power fuel cell densities of less than $2 \mu \mathrm{Wcm}^{-3}$, which makes them inefficient compared to piezoelectric and thermal generators that have fundamental power density limits of $30 \mu \mathrm{Wcm}^{-3}$ and $10 \mu \mathrm{Wcm}^{-3}{ }^{28}$ respectively. In order to address the issue, Kloke et $a^{29}$ has recently investigated a single layer design for glucose fuel cells by placing the anode and cathode side by side. As noted there, a single layer design is desirable because of simplified fabrication, reduced thickness and facilitated implementation of the fuel cell in implantable devices. Although it was demonstrated that such single layer fuel cells can produce excellent power output $\left(2.2 \mu \mathrm{W} \mathrm{cm}{ }^{-2}\right)$, their fabrication required over $50 \mu \mathrm{m}$ platinum sheets and no attempt was made at integrating them in high power density fuel cell units.

Here we demonstrate how the single layer design can be manufactured cost-efficiently on single wafers using standard fabrication protocols and integrated in both high surface area and low volume implantable devices. We start by presenting the fabrication protocol for the low-platinum single layer fuel cell (SLFC), followed by polarization curves for both electrodes in order to understand the limiting reactions and the effect of changes in reactant concentration on fuel cell performance. We then demonstrate how SLFCs can be designed to reduce mixed potential effects when used as coating layers for implantable devices. Finally we show how we can stack SLFCs to produce high power density fuel cell units.

\section{Results}

SLFC fabrication and characterization. The single-layer fuel cells (SLFCs) developed here are patterned directly on $500 \mu \mathrm{m}$ thick fused silica substrates (Fig. 1a) and subsequently diced to obtain $1 \mathrm{~cm}^{2}$ fuel cell layers. A concentric design where the anode is surrounded by the cathode was selected because, as will become apparent in the next sections, it increases the interface area between the electrodes and it helps increase glucose-oxygen separation when the layers are stacked. In order to achieve high effective surface area, a Raneytype alloy process is used for both the anode and the cathode. This process, first demonstrated by Gebhardt et al. ${ }^{30}$, involves the annealing of a thin layer of platinum with a non-noble metal followed by the chemical etching of the non-alloyed outer metal layer. In this paper nickel is used as the non-noble metal at the anode and aluminum at the cathode. We use a Ni/Pt alloy as anode for glucose oxidation because it has been shown elsewhere to exhibit greater selectivity towards glucose than other abiotic catalysts $^{14}$. The electrodes in the SLFCs presented here use only $100 \mathrm{~nm}$ of platinum, significantly less than in other works where metals such as zinc or nickel were electroplated on $50 \mu \mathrm{m}$ thick platinum foils ${ }^{29,31}$. The main issue with using such thin layers of platinum is that the electrode roughness that can be obtained using a Raney process is significantly lower resulting is smaller electrode surface area. Experiments with several anneal temperatures in the range $400^{\circ} \mathrm{C}-600^{\circ} \mathrm{C}$ have demonstrated that the roughness that can be obtained using a Raney-type process in the case of $100 \mathrm{~nm}$ $\mathrm{Pt} / 300 \mathrm{~nm}$ Ni peaks when the annealing temperature reaches $500^{\circ} \mathrm{C}$. For the cathode, a high surface area platinum surface was obtained by annealing $100 \mathrm{~nm} \mathrm{Pt} / 100 \mathrm{~nm} \mathrm{Al}$ at a low-temperature of $300^{\circ} \mathrm{C}$ and subsequently etching the aluminum with $\mathrm{NaOH}$. X-ray photoelectron spectroscopy (XPS) analysis was used to determine the metal composition at the anode surface before and after etching to ensure that no un-alloyed nickel was left behind (see Supplementary Fig. S1 online). The roughness of the electrodes is apparent from scanning electrode microscopic (SEM) images (Fig. 1c) and has been quantified using a cyclic voltammetry method. By estimating the charge under the hydrogen adsorption peaks in the cyclic voltammograms during cleaning of the samples, the roughness factor (RF) of the Raney-type $\mathrm{Ni} / \mathrm{Pt}$ anode annealed at $500^{\circ} \mathrm{C}$ was determined to be $238 \pm 15$. This is significantly higher than the RF of commercially available platinum foils $(30 \pm 4)$ but an order of magnitude lower than the RF values reported by Gebhardt et al. for $50 \mu \mathrm{m}$ thick Ni/Pt Raney films (RF $2000)^{30}$.

SLFC electrode characterization. The polarization curves of the anode and cathode in SLFCs provide useful information as to the limiting reactions of the fuel cell and the effect of variations in glucose and oxygen concentration. Fig. 2a shows the polarization curves for the $\mathrm{Pt} / \mathrm{Al}$ cathode at different oxygen and glucose concentrations. Two flow meters (0.2-2 SCFH) were used to adjust the ratio of air and nitrogen flowing in the $0.1 \mathrm{M}$ PBS solution and the temperature was maintained at $37^{\circ} \mathrm{C}$. It can be seen that at low oxygen concentrations $\left(7 \% \mathrm{O}_{2}\right.$ saturation) there are two distinct regions to the polarization curve, a linear ohmic region from 0 to $10 \mu \mathrm{Acm}^{-2}$ and a transport-limited region above $10 \mu \mathrm{Acm}^{-2}$. In the linear ohmic region the drop in voltage is due mainly to resistance in the electrolyte while in the transport-limited region the voltage drop is due to low oxygen concentration near the electrode surface. At high oxygen concentration $\left(21 \% \mathrm{O}_{2}\right.$ saturation) no transport limitedregion is observed under $30 \mu \mathrm{Acm}^{-2}$. The effect of glucose on the cathode is relatively small with voltage drops of less than $20 \mathrm{mV}$ at current densities in the range 0 to $30 \mathrm{\mu} \mathrm{Acm}^{-2}$ indicating that the $\mathrm{Pt} /$ $\mathrm{Al}$ alloy selectively catalyzes oxygen reduction in the presence of glucose. The electrode specific resistance in the linear regime is given by $\mathrm{R}=\Delta \mathrm{U} / \Delta \mathrm{j}=6.69 \mathrm{k} \Omega \mathrm{cm}^{-2}$. The cathode open circuit
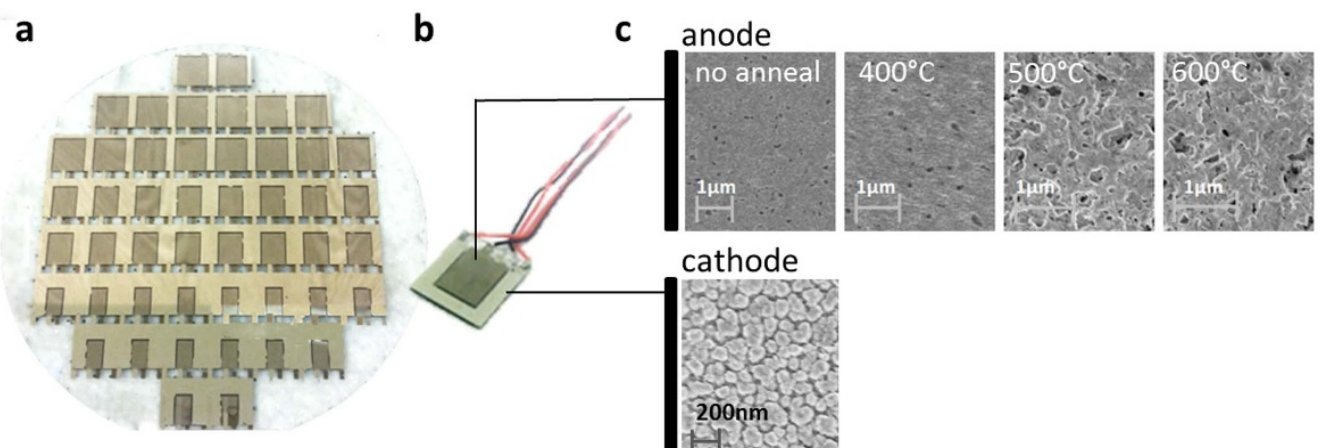

Figure 1 | Single Layer Fuel Cell devices. (a) fused silica substrate before dicing with single layer fuel cells (SLFC) patterned on both sides (b) a typical device used in this work with leads attached (c) scanning electron microscopic (SEM) images showing the high surface area Raney-alloy structure of the anode at different alloying temperatures and at the cathode. 
a

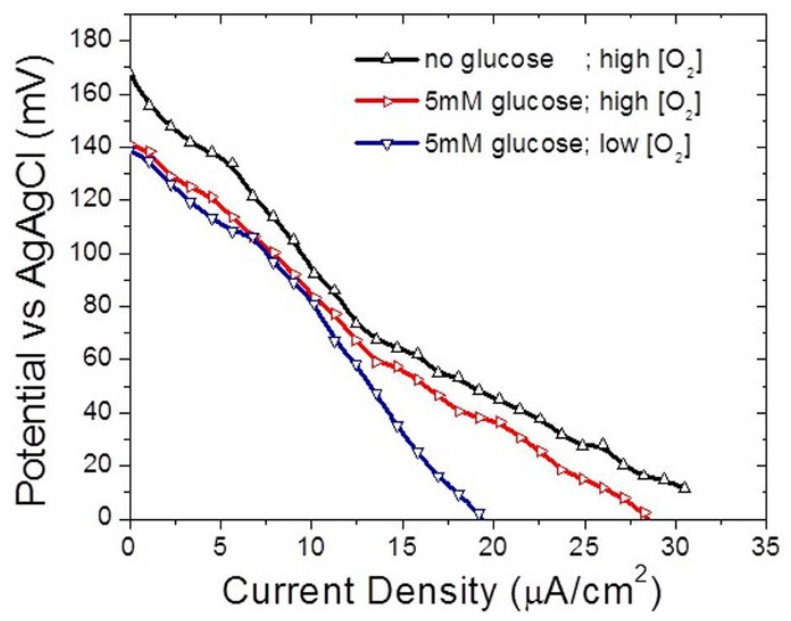

b

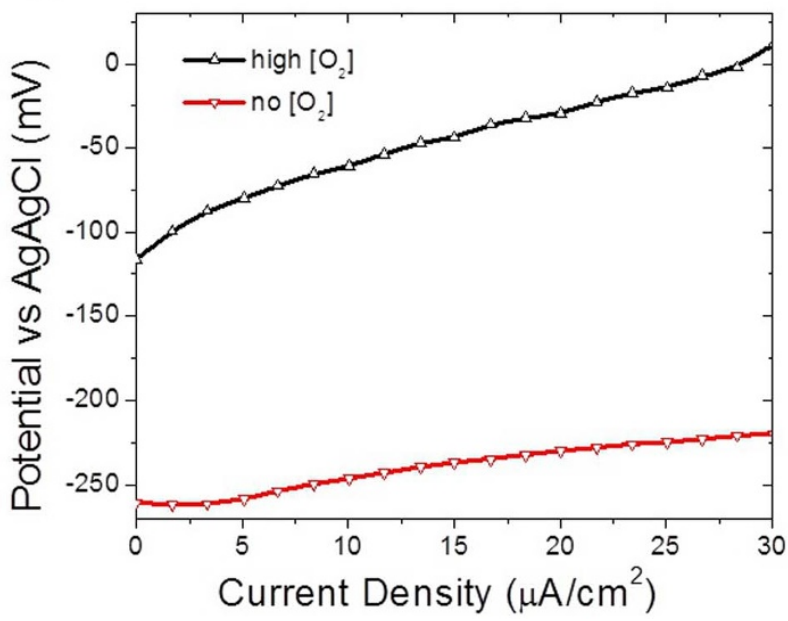

Figure $2 \mid$ Electrode polarization curves. (a) cathode $i-\mathrm{V}$ curves showing the effect of $5 \mathrm{mM}$ glucose in solution and the effect of low oxygen partial pressure ( $7 \%$ oxygen saturation) (b) anode $i-\mathrm{V}$ curves at high ( $21 \%$ saturation) and low ( $2 \%$ oxygen saturation) oxygen partial pressure.

The results represent the average of 3 measurements.

potential versus the $\mathrm{Ag} / \mathrm{AgCl}$ reference electrode is comparable to what was previously reported by Kerzenmacher et al. for Raney-type $\mathrm{Pt} / \mathrm{Al}$ alloys ${ }^{32}$.

For the $\mathrm{Pt} / \mathrm{Ni}$ anode the polarization curves in Fig. $2 \mathrm{~b}$ show that the potential is significantly lowered by the presence of oxygen, however because glucose is present in high concentrations in interstitial fluid, there is no transport limited region in the 0 to $30 \mu \mathrm{Acm}^{-2}$ range. The electrode specific resistance increases from $1.31 \mathrm{k} \Omega \mathrm{cm}^{-2}$ when only nitrogen flows in solution $\left(2 \% \mathrm{O}_{2}\right.$ saturation) to $3.21 \mathrm{k} \Omega \mathrm{cm}^{-2}$ when only air flows in solution $\left(21 \% \mathrm{O}_{2}\right.$ saturation). The polarization curves presented in this section indicate that in a SLFC the polarization of the cell voltage is dominated by resistance at the cathode even when the oxygen partial pressure is above physiological levels. It can also be seen that a decrease in oxygen has a mixed effect on the polarization curve of the fuel cell since it decreases the resistance at the anode but creates mass transport limited effects at the cathode.

SLFCs as coating layers to implantable devices. SLFCs are attractive because they can be integrated directly as coating layers for implantable devices. However, as the polarization curve for the anode indicates, the presence of oxygen can significantly reduce the performance of the anode. In addition, we observed from electrode polarization curves that for the cathode at low oxygen partial pressure there is a limiting current density above which the oxygen reduction reaction becomes transport limited. To address this, we have developed several designs that minimize these oxygen and transport limiting effects. First we look at the effect of varying the cathode to anode area ratio (denoted as $n=\mathrm{A}_{\text {cathode }} / \mathrm{A}_{\text {anode }}$ ) in order to determine the optimal configuration such that the fuel cell is not limited by oxygen transport at the cathode. From Fig. 3a we observe that at high oxygen partial pressures the maximum current density drawn from the fuel cell increases with increasing $n$. A peak power output of $1.21 \mu \mathrm{Wcm}^{-2}$ is observed for SLFCs with $n=3.7$, a $50 \%$ increase over SLFCs with $n=0.47$, indicating that it's beneficial to have a larger cathode surface area. This is expected since, as mentioned in the previous section, the polarization of the cell voltage is mainly driven by resistance at the cathode. In addition, at low oxygen partial pressure we expect the advantage of a lager cathode area to be even more accentuated due to higher electrode specific resistance at the cathode in the transport-limited regime.

Using a similar approach to the above, we can also demonstrate how SLFC designs with high interface area between the electrodes can minimize mixed potential effects at the anode and improve the performance of the fuel cell. We achieve this by having an interdigital interface, or comb-like interface, between the anode and the cathode as can be seen in Fig. 3b. Interdigital electrodes have been demonstrated before for electrochemical sensors ${ }^{33}$, however our approach is the first implementation for non-enzymatic glucose fuel cells. Here the electrodes are separated by $500 \mu \mathrm{m}$ and the aim of the electrode pattern is to increase the area of oxygen depletion over the anode and decrease the ohmic resistance between the electrodes. Since oxygen consumption is proportional to the current drawn from the fuel cell, the effect of oxygen depletion at the anode gets more significant when the fuel cell operates at high current densities. Fig. $3 \mathrm{~b}$ shows that the interdigital designs increases the peak power output of the SLFC from $1.05 \mu \mathrm{Wcm}^{-2}$ to just over $1.32 \mu \mathrm{Wcm}^{-2}$. The reported peak power output represents the average of 3 different experiments with sample standard deviation of $\pm 0.09 \mu \mathrm{Wcm}^{-2}$ for the interdigital design and $\pm 0.12 \mu \mathrm{Wcm}^{-2}$ the non-interdigital design. The experiments described above were performed at high oxygen partial pressure (21\% oxygen saturation) in order to avoid any experimental errors due to the flow of nitrogen in solution which is hard to control accurately. In another experiment, we lowered the oxygen concentration by increasing the flow of nitrogen in solution (7\% oxygen saturation) and observed a large increase in power output for both interdigital and non-interdigital designs. This trend is consistent with our observations from the anode polarization curves that predict a decrease in anode potential at lower oxygen concentrations. A similar increase in fuel cell performance was observed by Sharma et $a^{23}$ when the fuel cells were tested in-vivo at lower oxygen partial pressure. As shown in Fig. $3 \mathrm{~b}$ the interdigital SLFC has a peak performance of approximately $2.01 \mu \mathrm{Wcm}^{-2}$ at low oxygen partial pressure, compared to $1.36 \mu \mathrm{Wcm}^{-2}$ for the non-interdigital SLFC. The improvement in peak power output is more significant in the interdigital case (52.3\% increase compared to $29.3 \%$ ) likely due to increased oxygen depletion over the anode. As was previously reported, a change in oxygen concentration at the anode surface has greater effect on fuel cell performance at lower oxygen partial pressures ${ }^{26}$. The peak power changes in this experiment are therefore consistent with that observation. In addition, the reduced ionic resistance between the anode and the cathode due to the high interface area also contributes to the increased performance of the interdigital design. 
a

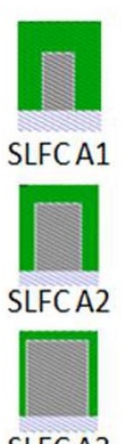

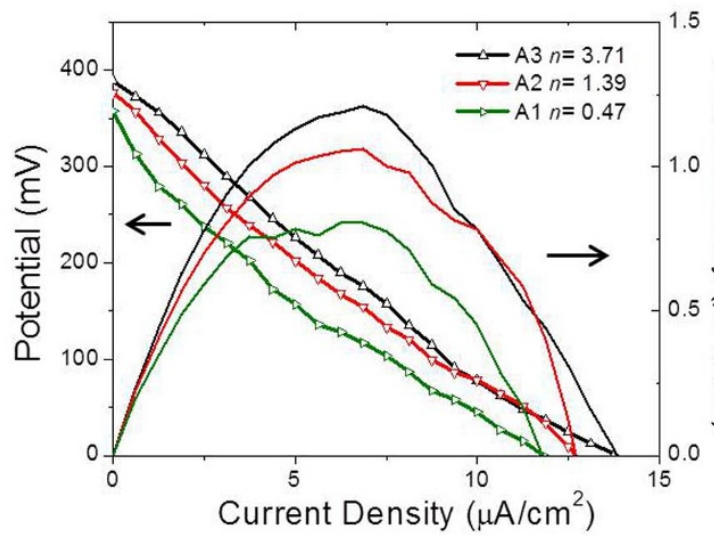

b

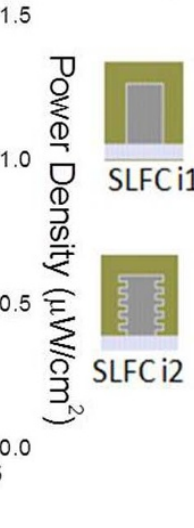

Figure 3 SLFC as coating layers. (a) SLFCs used to test the effect $\mathrm{n}=\mathrm{A}_{\text {cathode }} / \mathrm{A}_{\text {anode }}$ on fuel cell performance (here for SLFC A1 $n=3.7$, SLFC A2 $n=1.39$, SLFC A3 $n=0.47$ ) (b) interdigital electrode fuel cells used to test the effect of interface area and oxygen concentration on fuel cell performance. The results represent the average of 3 measurements.

SLFCs in stacked configuration. The greatest advantage of SLFCs over other non-enzymatic glucose fuel cells designs is that they can be integrated in very compact fuel cell units for volume sensitive implantable devices. As discussed previously, the glucose fuel cells developed so far have been intended to be used as coating layers for implantable devices since their thickness and complicated stacked design makes them unsuitable for low volume applications. The SLFCs developed here, not only can be easily stacked, but doing so greatly increases their performance. Stacking the SLFC can reduce the amount of oxygen reaching the anode, as illustrated in Fig. 4a, because only a small volume of interstitial fluid is allowed to diffuse through the sides and between the fuel cell layers. Fig. $4 \mathrm{~b}$ shows the effect of stacking on the overall performance of a SLFC. The gap $\delta$ between the SLFCs determines the amount of reactants that that can diffuse through the sides of the stacked fuel cell unit and over the electrodes. Using this approach some of the oxygen in solution reacts at the cathode before it diffuses to the anode allowing glucose oxidation to proceed at low oxygen concentrations as illustrated in Fig. 4a. As discussed previously, some of the glucose reacts at the Pt/ Al cathode, however the effect on the stacked SLFC's performance is small because of the large difference in oxygen and glucose physiological concentration. In interstitial tissue, the glucose concentration is approximately $5 \mathrm{mmol} \mathrm{L}{ }^{-1}$ while that of oxygen is less than $0.2 \mathrm{mmol} \mathrm{L}^{-1}$. Decreasing the gap $\delta$ between the fuel cell layers can increase the peak power output of the SLFC. It can be seen in Fig. $4 \mathrm{~b}$ that the increase can result in over 2 fold increase in power output per SLFC over the case where there is no stacking. For a SLFC A1 type fuel cell, a peak power output of $1.88 \mu \mathrm{W} / \mathrm{cm}^{2}$ is obtained when $\delta$ is $0.5 \mathrm{~mm}$. Although the fuel cell layers could potentially be stacked event closer together $(\delta \leq 0.5 \mathrm{~mm})$, this is not easily achievable for the current design, because of the thickness of the wires that were used as electrode connections. The experiments were performed at $37^{\circ}$ in $0.1 \mathrm{M}$ PBS solution with physiological levels of glucose $\left(5 \mathrm{mmol} \mathrm{L}^{-1}\right)$ and dissolved oxygen in solution $\left(0.2 \mathrm{mmol} \mathrm{L}^{-1}\right)$.

Integrated fuel cell unit. In order to demonstrate the potential of SLFCs to be integrated in implantable devices as highly compact power sources we have assembled a fuel cell unit with stacked SLFCs connected externally in parallel. The holder was printed using a 3D printer. The assembled device in Fig. 5a has a volume of approximately $1 \mathrm{~cm}^{3}$ and can accommodate 12 SLFCs printed on both sides of $1 \mathrm{~cm}$ by $1 \mathrm{~cm}$ diced pieces of $500 \mu \mathrm{m}$ thick fused silica wafers. That represents $12 \mathrm{~cm}^{2}$ of fuel cell surface area exposed to

a

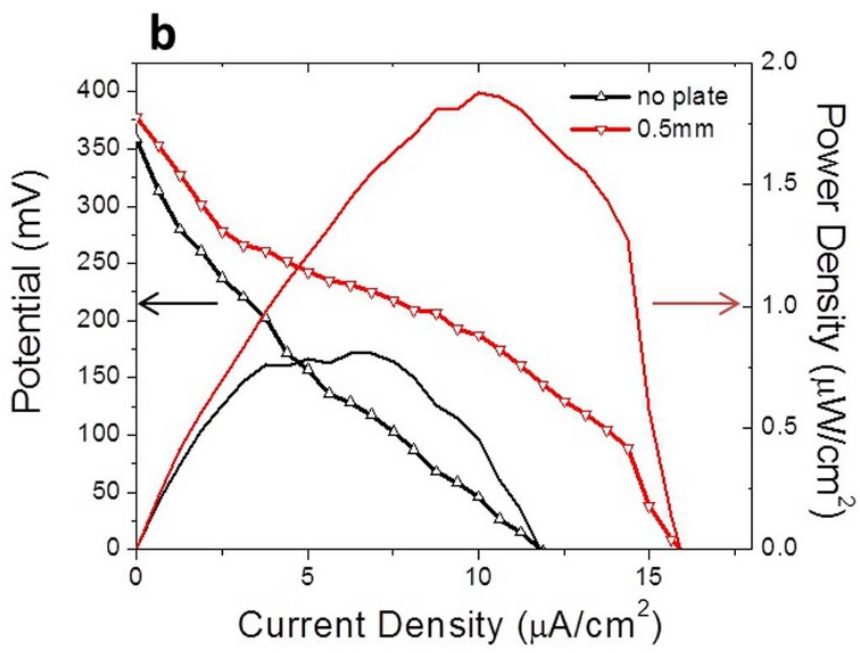

Figure $4 \mid$ SLFC in stacked configuration. (a) illustration demonstrating how confining the reactants diffusion can reduce the amount of oxygen at the anode (b) confined diffusion effect on fuel cell performance showing the increase in SLFC A1 performance when there is plate 0.5 mm above the SLFC. The results represent the average of 3 measurements. 

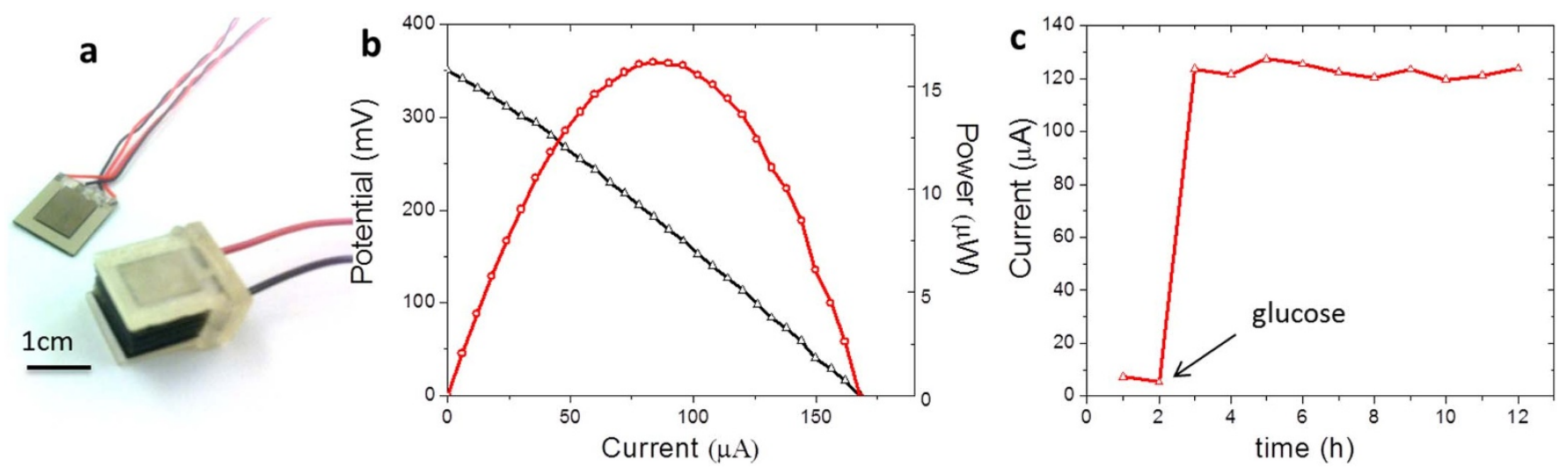

Figure $5 \mid$ Confined Diffusion effect on performance. (a) picture of one double sided SLFC along with a stack of 12SLFCs (b) performance of the 12 SLFCs stack connected in parallel (c) chronoamperometric response at $0.1 \mathrm{~V}$ in $0.01 \mathrm{M}$ PBS solution for the first $2 \mathrm{~h}$ and after the addition of $5 \times 10^{-3} \mathrm{molL}^{-1}$ glucose.

solution. For comparison purposes an oxygen depletion design type fuel cell that we have previously developed ${ }^{26}$ had a thickness of $0.5 \mathrm{~cm}$, a total volume of $2 \mathrm{~cm}^{3}$ and a surface area of $1 \mathrm{~cm}^{2}$ exposed to solution. The fuel cell had a power output of $2 \mu \mathrm{Wcm}^{-2}$ corresponding to a volumetric power output of roughly $1 \mu \mathrm{Wcm}^{-3}$. Fig. $5 \mathrm{~b}$ shows the cell potential and power density versus current density for the stacked fuel cell unit in Fig. 5a. It can be seen that the peak volumetric power output is $16 \mu \mathrm{Wcm}^{-3}$ roughly 16 times higher than for the depletion design type fuel cell. The sweep rate used here is $18 \mu \mathrm{A} \mathrm{h}^{-1}$. The performance is lower than the expected peak performance of 12 SLFCs connected in parallel, because of resistance losses in external SLFC connections.

Chronoamperometric experiments were also performed to demonstrate the long-term stability of the fuel cell unit. Fig. $5 \mathrm{c}$ shows the chronoamperometric response at $100 \mathrm{mV}$ over a period of 12 hours. For the first 2 hours the fuel cells was kept in 0.01 M PBS solution after which $5 \mathrm{mM}$ glucose was added to the solution. It can be seen that a stable current output of $123 \mu \mathrm{A}$ was obtained following the addition of glucose and less than $\pm 10 \%$ fluctuation was observed during the entire period. In addition, this stable current output at $100 \mathrm{mV}$ is consistent with the data presented for the polarization curve in Fig. $5 \mathrm{~b}$ demonstrating that a sweep rate of $18 \mu \mathrm{A} \mathrm{h}^{-1}$ did not lead to an overestimation of the performance.

\section{Discussion}

The results presented in this paper demonstrate the potential of SLFCs to be integrated as high-performance low-cost glucose power sources in implantable devices. Unlike other non-enzymatic fuel cells proposed previously, the SLFCs are thin and easy to fabricate and assembled using standard semiconductor processing technology. In addition, each electrode is fabricated using $100 \mathrm{~nm}$ evaporated platinum, which is significantly less than in other designs where $50 \mu \mathrm{m}$ thick platinum foils were used for fabricating Raney-type $\mathrm{Pt} / \mathrm{Zn}$ alloys $^{31}$. Here, it was demonstrated that an inter-digital type SLFC can achieve up to $2.01 \mu \mathrm{Wcm}^{-2}$ peak power output at physiological levels of glucose and oxygen and that a stacked fuel cell unit of 12 SLFCs can provide a volumetric power output of at least $16 \mu \mathrm{Wcm}^{-3}$. It is important to note that here the performance is measured in terms of SLFC area which includes both patterned electrodes. The state-of-the-art depletion design fuel cells quote a power output of 2 to $4.4 \mu \mathrm{Wcm}^{-2}$ per area exposed to the solution, which is just the geometrical surface area of the cathode ${ }^{26,27}$ and does not take into account the thickness of the assembled fuel cell. In depletion design fuel cells the cathode is placed on top of the anode resulting in complicated assembly which makes them unsuitable for stacking and low volume applications. This makes such fuel cells hard to compare on volumetric power output basis with the SLFCs presented in this paper. The single layer fuel cell presented by Kloke $e t a l^{29}$ has a peak power output of $2.2 \mu \mathrm{W} \mathrm{cm}$ cm $^{-2}$ however it is not fabricated on a single substrate and has not been integrated in high power density fuel cell units as is the case in this paper. The performance of the SLFCs can be improved further by developing more selective anodic catalysts $^{14}$ or by increasing the surface area of the electrodes in the current design. Kloke et al. ${ }^{29}$ has recently demonstrated that a Raneytype platinum zinc catalyst obtained from $50 \mu \mathrm{m}$ thick platinum foils and $30 \mu \mathrm{m}$ thick layer of zinc can have an open circuit voltage of $-400 \mathrm{mV}$, significantly lower than the anode we presented here. In addition surface area of the electrodes can be increased by immobilizing carbon nanotubes onto the fused silica wafer before electrode patterning. Carbon nanotubes have been used for a long time to increase the area of enzymatic fuel cells ${ }^{34}$. Some groups have developed and characterized electrodes with embedded multiwall carbon nanotubes ${ }^{35}$ but have yet to be implemented in non-enzymatic glucose fuel cell systems.

\section{Methods}

Fabrication. The fabrications steps for the fuel cells described here were performed at the Cornell Nanofabrication Facility. $500 \mu \mathrm{m}$ thick fused silica wafers were used due to the fact that electrode can be patterned directly on them without the need of depositing a silicon oxide layer. The electrodes were patterned one at a time using a LOR lift-off process. First the anode was patterned using E-beam evaporation (CHA Evaporator) where $20 \mathrm{~nm}$ of titanium was deposited in order to promote adhesion followed by $100 \mathrm{~nm}$ of platinum and $300 \mathrm{~nm}$ of nickel. The wafer was subsequently annealed for 2 hours in nitrogen gas at $600^{\circ} \mathrm{C}$ (MRL Industries Furnace). In order to avoid oxide formation when opening and closing the furnace door, the stand-by temperature of the furnace was kept bellow $300^{\circ} \mathrm{C}$. In order to obtain a high surface area Raney-type surface the nickel was etched by keeping the wafers in a $1: 1$ solution of concentrated sulfuric acid and nitric acid for $12 \mathrm{~h}$. The cathode was patterned using E-beam evaporation of $20 \mathrm{~nm}$ of titanium followed by $100 \mathrm{~nm}$ of platinum and $100 \mathrm{~nm}$ aluminum. The wafer was subsequently annealed for 1 hour in nitrogen gas at $300^{\circ} \mathrm{C}$ followed by the etching the aluminum in $0.1 \mathrm{M} \mathrm{NaOH}$ solution. The fused silica wafers were then diced (K\&S 7100 Dicing Saw) into $10 \mathrm{~mm}$ by $12 \mathrm{~mm}$ pieces. Copper wires (30 gauge) were soldered directly onto the electrodes.

Cleaning and activation. After dicing the fuel cells were cleaned under oxygen plasma for $10 \mathrm{~min}$ to remove any resist residue at the surface. Both electrodes are than subject to cyclic voltammetry in $0.5 \mathrm{M}$ sulfuric acid solution for 10 cycles at $50 \mathrm{mVs}^{-1}$. Following a method previously described by Kerzenmacher et al. the cathodes were subjected for $30 \mathrm{~min}$ to an oxidative current density of $44 \mu \mathrm{Acm}^{-2}$ in $0.01 \mathrm{M}$ phosphate buffer saline solution(Sigma P-5368 0.138 M NaCl) with pH 7.4 at $7 \%$ oxygen saturation without glucose.

Experimental setup and conditions. The experimental setup used in this paper has been previously described by the authors elsewhere ${ }^{26}$. All experiments were performed in $500 \mathrm{~mL} 0.01 \mathrm{M} \mathrm{PBS}$ solution ( $\mathrm{pH} \mathrm{7.4)}$ at $37^{\circ} \mathrm{C}$. When specified, glucose was added at physiological levels of $5 \mathrm{mmol} \mathrm{L}^{-1}$. The solution was replaced after each experiment to ensure low contamination. Two flow meters (VWR 0.2-20 SCFM) were used to adjust the ratio of air and nitrogen (Airgas NI-200) flowing in the solution. In most experiments air was constantly being bubbled through at $0.2 \mathrm{SCFH}$ to ensure that the oxygen levels remained constant throughout the experiment. The 
measured dissolved oxygen saturation level was $(21 \pm 0.5) \%$. Where specified $0.6 \mathrm{SCFH}$ nitrogen gas was mixed with the air in order to decrease the oxygen concentration in solution. The corresponding dissolved oxygen level was measured to $(7 \pm 0.5) \%$ saturation corresponding to the upper physiological oxygen saturation level $(7 \% \text { or about } 0.06 \mathrm{mM})^{31}$. The dissolved oxygen measurements were performed using a Dissolved Oxygen Pen (850045 Sper Scientific). The solution was stirred for 3 hours prior to performing current sweep experiments in order to improve glucose mixing in the solution, however it was not stirred during the experiments.

Instrumentation. A Keithley 2400 Source-meter was used to apply a current sweep across the fuel cells and a Keithley 2000 Multi-meter equipped with a scanner card was used to take the voltage measurements of individual electrode potentials versus the reference electrode. The current sweep and channel switching was remotely controlled using a LABVIEW program. All current sweeps were performed at a sweep rate of $18 \mu \mathrm{A} \mathrm{h}^{-1}$, starting $0 \mu \mathrm{A}$ and increasing the current by $0.5 \mu \mathrm{A}$ every $100 \mathrm{~s}$. A silver-silver chloride reference (Aldrich Double junction $\mathrm{Ag} / \mathrm{AgCl}$ reference) electrode was used as the reference against which electrode potentials were measured.

1. Vincent, C. A. Lithium batteries: a 50-year perspective, 1959-2009. Solid State Ionics 134, 159-167 (2000)

2. Kurtz, S. M. et al. Implantation Trends and Patient Profiles for Pacemakers and Implantable Cardioverter Defibrillators in the United States: 1993-2006. Pacing and Clinical Electrophysiology 33, 705-711 (2010).

3. Schmidt, C. L. \& Skarstad, P. M. The future of lithium and lithium-ion batteries in implantable medical devices. Journal of Power Sources 97-98, 742-746 (2001).

4. Grill, W. M. \& Wei, X. F. in Engineering in Medicine and Biology Society, 2009. EMBC 2009. Annual International Conference of the IEEE 3298-3301 (2009).

5. Heller, A. Potentially implantable miniature batteries. Analytical and Bioanalytical Chemistry 385, 469-473 (2006).

6. Wei, X. \& Liu, J. Power sources and electrical recharging strategies for implantable medical devices. Frontiers of Energy and Power Engineering in China 2, 1-13 (2008).

7. Qi, Y. \& McAlpine, M. C. Nanotechnology-enabled flexible and biocompatible energy harvesting. Energy \& Environmental Science 3, 1275-1285 (2010)

8. Khaligh, A., Peng, Z. \& Cong, Z. Kinetic Energy Harvesting Using Piezoelectric and Electromagnetic Technologies-2014;State of the Art. Industrial Electronics, IEEE Transactions on 57, 850-860 (2010).

9. Zhong Lin, W. in Nanoelectronics Conference (INEC). 2010 3rd International 63-64 (2010).

10. Stark, I. in Wearable and Implantable Body Sensor Networks, 2006. BSN 2006. International Workshop on 19-22 (2006).

11. Heller, A. Miniature biofuel cells. Physical Chemistry Chemical Physics 6, 209-216 (2004).

12. Schröder, U. From In Vitro to In Vivo-Biofuel Cells Are Maturing. Angewandte Chemie International Edition 51, 7370-7372 (2012).

13. Justin, G. A., Yingze, Z., Mingui, S. \& Sclabassi, R. in Engineering in Medicine and Biology Society. 2004. IEMBS '04. 26th Annual International Conference of the IEEE Vol. 2, 4096-4099 (2004).

14. Kerzenmacher, S., Ducrée, J., Zengerle, R. \& von Stetten, F. Energy harvesting by implantable abiotically catalyzed glucose fuel cells. Journal of Power Sources 182, 1-17 (2008).

15. Moehlenbrock, M. J. \& Minteer, S. D. Extended lifetime biofuel cells. Chemical Society Reviews 37, 1188-1196 (2008).

16. Rengaraj, S., Kavanagh, P. \& Leech, D. A comparison of redox polymer and enzyme co-immobilization on carbon electrodes to provide membrane-less glucose/O2 enzymatic fuel cells with improved power output and stability. Biosensors and Bioelectronics 30, 294-299 (2011).

17. Cinquin, P. et al. A glucose biofuel cell implanted in rats. PLoS ONE 5 e10476-e10476 (2010)

18. Kim, J., Jia, H. \& Wang, P. Challenges in biocatalysis for enzyme-based biofuel cells. Biotechnology Advances 24, 296-308 (2006).

19. Zebda, A. et al. Mediatorless high-power glucose biofuel cells based on compressed carbon nanotube-enzyme electrodes. Nature communications $\mathbf{2}, 370$ (2011).

20. Halámková, L. et al. Implanted Biofuel Cell Operating in a Living Snail. Journal of the American Chemical Society 134, 5040-5043 (2012).
21. Szczupak, A. et al. Living battery - biofuel cells operating in vivo in clams. Energy \& Environmental Science 5, 8891-8895 (2012).

22. Drake, R. F., Kusserow, B. K., Messinge, S. \& Matsuda, S. A Tissue Implantable Fuel Cell Power Supply. Transactions American Society for Artificial Internal Organs 16, 199-\& (1970).

23. Sharma, T. et al. Mesoporous silica as a membrane for ultra-thin implantable direct glucose fuel cells. Lab on a Chip 11, 2460-2465 (2011).

24. Rao, J. R., Richter, G. J., Von Sturm, F. \& Weidlich, E. The performance of glucose electrodes and the characteristics of different biofuel cell constructions. Bioelectrochemistry and Bioenergetics 3, 139-150 (1976).

25. Kerzenmacher, S., Ducrée, J., Zengerle, R. \& von Stetten, F. An abiotically catalyzed glucose fuel cell for powering medical implants: Reconstructed manufacturing protocol and analysis of performance. Journal of Power Sources 182, 66-75 (2008).

26. Oncescu, V. \& Erickson, D. A microfabricated low cost enzyme-free glucose fuel cell for powering low-power implantable devices. Journal of Power Sources 196, 9169-9175 (2011).

27. Kerzenmacher, S., Kraling, U., Metz, T., Zengerle, R. \& von Stetten, F. A potentially implantable glucose fuel cell with Raney-platinum film electrodes for improved hydrolytic and oxidative stability. Journal of Power Sources 196, 1264-1272 (2011).

28. Mitcheson, P. D. in Engineering in Medicine and Biology Society (EMBC). Annual International Conference of the IEEE 3432-3436 (2010).

29. Kloke, A. et al. A Single Layer Glucose Fuel Cell Intended as Power Supplying Coating for Medical Implants. Fuel Cells 11, 316-326 (2011).

30. Gebhardt, U., Rao, J. R. \& Richter, G. J. A special type of raney-alloy catalyst used in compact biofuel cells. Journal of Applied Electrochemistry 6, 127-134 (1976).

31. Kerzenmacher, S., Schroeder, M., Brämer, R., Zengerle, R. \& von Stetten, F. Raney platinum film electrodes for potentially implantable glucose fuel cells. Part 1: Nickel-free glucose oxidation anodes. Journal of Power Sources 195, 6516-6523 (2010).

32. Kerzenmacher, S. et al. Raney-platinum film electrodes for potentially implantable glucose fuel cells. Part 2: Glucose-tolerant oxygen reduction cathodes. Journal of Power Sources 195, 6524-6531 (2010).

33. Van Gerwen, P. et al. Nanoscaled interdigitated electrode arrays for biochemical sensors. Sensors and Actuators B: Chemical 49, 73-80 (1998).

34. Davis, J. J., Coles, R. J., Allen, H. \& Hill, O. Protein electrochemistry at carbon nanotube electrodes. Journal of Electroanalytical Chemistry 440, 279-282 (1997).

35. Prilutsky, S. et al. Anodes for glucose fuel cells based on carbonized nanofibers with embedded carbon nanotubes. Electrochimica Acta 55, 3694-3702 (2010).

\section{Acknowledgments}

This work was supported by the Office of Naval Research under grant "Autonomous Microfluidic Devices for Battlefield Health Assessment and Treatment" which has award number N000141010115. V.O. acknowledges the support of the National Science and Engineering Research Council of Canada (NSERC) through a Postgraduate scholarship. The fabrication steps described in this paper were carried out at the Cornell Nanoscale Facility (CNF) and the Nanobiotechnology Center at Cornell University (NBTC). The XPS analysis was performed by John Shu at the Cornell Center for Material Research (CCMR).

\section{Author contributions}

D.E. designed the project. V.O. performed the research. All authors wrote and reviewed the manuscript.

\section{Additional information}

Supplementary information accompanies this paper at http://www.nature.com/ scientificreports

Competing financial interests: The authors declare no competing financial interests. License: This work is licensed under a Creative Commons Attribution-NonCommercial-NoDerivs 3.0 Unported License. To view a copy of this license, visit http://creativecommons.org/licenses/by-nc-nd/3.0/

How to cite this article: Oncescu, V. \& Erickson, D. High volumetric power density, non-enzymatic, glucose fuel cells. Sci. Rep. 3, 1226; DOI:10.1038/srep01226 (2013). 